\title{
Author Correction: Gene isoforms as expression- based biomarkers predictive of drug response in vitro
}

\author{
Zhaleh Safikhani, ${ }^{1,2}$, Petr Smirnov (10 1, Kelsie L. Thu ${ }^{1,3}$, Jennifer Silvester ${ }^{1,3}$, Nehme El-Hachem ${ }^{3}$, Rene Quevedo ${ }^{1,2}$, \\ Mathieu Lupien ${ }^{1,2}$, Tak W. Mak ${ }^{1,2,4}$, David Cescon ${ }^{1,4,5}$ \& Benjamin Haibe-Kains (1) 1,2,6,7
}

Correction to: Nature Communications https://doi.org/10.1038/s41467-017-01153-8, published online 24 October 2017

In the original version of this Article, financial support was not fully acknowledged. The PDF and HTML versions of the Article have now been corrected to include the following:

The research was supported by a Stand Up To Cancer Canada-Canadian Cancer Society Breast Cancer Dream Team Research Funding, with supplemental support of the Ontario Institute for Cancer Research through funding provided by the Government of Ontario (Funding Award Number: SU2C-AACR-DT-18-15). Stand Up To Cancer Canada is a program of the Entertainment Industry Foundation Canada. Research funding is administered by the American Association for Cancer Research International-Canada, the Scientific Partner of SU2C Canada.

Published online: 09 January 2018

\footnotetext{
(i) Open Access This article is licensed under a Creative Commons Attribution 4.0 International License, which permits use, sharing, adaptation, distribution and reproduction in any medium or format, as long as you give appropriate credit to the original author(s) and the source, provide a link to the Creative Commons license, and indicate if changes were made. The images or other third party material in this article are included in the article's Creative Commons license, unless indicated otherwise in a credit line to the material. If material is not included in the article's Creative Commons license and your intended use is not permitted by statutory regulation or exceeds the permitted use, you will need to obtain permission directly from the copyright holder. To view a copy of this license, visit http://creativecommons.org/licenses/by/4.0/.
}

(C) The Author(s) 2018

\footnotetext{
${ }^{1}$ Princess Margaret Cancer Centre, University Health Network, 101 College Street, Toronto, ON M5G1L7, Canada. ${ }^{2}$ Department of Medical Biophysics, University of Toronto, 101 College Street, Toronto, ON M5G1L7, Canada. ${ }^{3}$ Institut de recherches cliniques de Montréal, 110 Pine Avenue West, Montreal, QC H2W 1R7, Canada. ${ }^{4}$ Campbell Family Institute for Breast Cancer Research, 620 University Avenue, Toronto, ON M5G2C1, Canada. ${ }^{5}$ Division of Medical Oncology and Hematology, Department of Medicine, University of Toronto, 27 King's College Circle, Toronto, ON M5S 1A1, Canada. ${ }^{6}$ Department of Computer Science, University of Toronto, 10 King's College Road, Toronto, ON M5S 3G4, Canada. 7 Ontario Institute of Cancer Research, 661 University Ave, Suite 510, Toronto, ON M5G 0A3, Canada. Correspondence and requests for materials should be addressed to B.H-K. (email: bhaibeka@gmail.com)
} 